\title{
Editorial
}

\section{Gaming and gamification of pricing}

Journal of Revenue and Pricing Management (2014) 13, 163. doi:10.1057/rpm.2014.15

It's as if play has come to work. Once upon a time only geeks played with video games, whereas nowadays this niche activity has gone mainstream with significant numbers across all demography cohorts whether it is an Xbox or Wii. In 2013, Grond Theft Auto and Call for Duty each generated US $\$ 1$ billion in 3 days. Gaming consoles have become part of our daily life as technology is changing play and the experience economy. A number of factors have brought about this, including the rise of the smartphone, a networked society and a culture of immediacy. Technology plays such an important part in today's society that word Gomificotion is crept into our business vocabulary. Gamification is the process of adding mechanics to processes, programs and platforms that wouldn't traditionally use such concepts (Swan, 2012). As Insley and Nunan (2014) highlight, gamification in the retail sector is changing the whole concept of being online from co-creation and new experience. Retailers are working to make shopping more fun via 'shoppertainment'. In China, the country's biggest food e-commerce site, Yihaodian (yhd.com), announced plans to open 1000 3D augmented reality grocery stores in blank city spaces and landmarks letting customers scan and buy. As Insley and Nunan report gamification and pricing adds a sense of self-control over purchases as online shoppers gain a feeling on the right purchase all the right time, all of which is the essence of the Revenue Management.

From a pricing perspective, gamification allows retailers to experiment and engage. Price has never been fixed in the realms of Revenue Management and now with gamification is spreading to new industries as consumers anticipate, negotiate and manipulate price. For example, Netotiate.com is allowing consumers to bid for better prices for products, whereas scorebig. com allows sports fans to bid for sport and live entertainment by naming the price they want to pay for (Future Foundation, 2014).

\section{REFERENCES}

Future Foundation (2014) The gamification of price, http:// nvision.futurefoundation.net/, accessed 14 April 2014.

Insley, V. and Nunan, D. (2014) Gamifkation and the online retail experience, International Journal of Retail \& Distribution Management, 5(42): http://www.emeraldinsightcom/journals.hlm?articleid17109464, accessed 13 May 2014.

Swan, C (2012) Gamification: A new way to shape behaviour. Communication world. May-June, pp. 13-14.

Ian Yeoman Editor E-mail: ian.yeoman@vuw.ac.nz 